\title{
Having Effective Communication Skills are Indispensable for the Successful Career of Engineering Students
}

\author{
B. Balaji Reddy ${ }^{1}$, M.M. Gopi ${ }^{2}$, Y. Aneel ${ }^{3}$ \\ ${ }^{I}$ (Professor of English,Department of HBS,Sri Venkatesa Perumal College of Engg. \& Technology, \\ RVS Nagar, K.N.Road, Puttur-517583,Chittoor (Dist), A.P. (State), INDIA. \\ ${ }^{2}$ (Asst. Professor of English,Department of HBS,Sri Venkatesa Perumal College of Engg. \& Technology, \\ RVS Nagar, K.N.Road, Puttur-517583, Chittoor (Dist), A.P. (State), INDIA. \\ ${ }^{3}$ (Asst. Professor of English,Department of B\&HS, Siddharth Institute of Engineering \& Technology, \\ Narayanavanam Road, Puttur-517583,Chittoor (Dist), A.P. (State), INDIA.
}

\begin{abstract}
Effective communication skills are extremely important for the successful career of present engineering students. Candidly speaking, effective communications skills are equally essential for everyone in today's ultra competitive business world. In the existing globalization scenario, most of the MNC's are searching for a right and suitable candidate with sound knowledge in communication skills in addition to the hard skills. Unfortunately most of the present day so-called engineering students are not up to the mark in communication skills and as a result they are disqualified. This present paper of us tries to focus on why effective communication skills are incredibly important and also a few suggestions that are highly beneficial in overcoming the most common communicative problems of engineering students.
\end{abstract}

Key Words: Effective communication skills, engineering students, important, overcome, various

\section{Introduction}

The success of an engineering student depends on the ability to communicative effectively in today's high speed world. In such a life effective communication holds the key. The success of Indian technologists in the last one decade is attributed to the fruitful mix of their strong knowledge in the core technology and English language skills. At the same time, thousand are losing job opportunities owing to the lack of the same said skills. Surveys have shown that out of a large number of professionals being produced every year only $10 \%$ are employable in various industries. The engineering students of all the streams should bear one thing clearly in their minds i.e. having required hard skills are not only adequate for their upcoming career but also effective communication skills are utmost important and very much needed.

\section{Important Effective Communication Skills for the Engineering Students}

Various eminent personalities have defined communication in many ways. One of them, by name Rudyard Kipling said, "Words are, of course, the most powerful drug used by mankind". Though it seems absolutely correct up to some extent, but this present quote of Kipling fails to communication why because communication is far more than words. Effective communication is about more than just exchanging information. Effective communication combines a set of skills such as non-verbal communication, attentive listening, LSRW skills, ability to present clearly and confidently to the audience etc. It is generally expected that engineering students should be equipped with a balance of technical knowledge in addition to the relevant communication and soft skills. The MNC's are now eagerly looking for the right candidates who possess strong communication skills to meet the challenges of the current global job market.

The following are the most important communication skills that are to be practiced and developed by the young engineering students:

- Good speaking skills: The need for giving emphasis on the English speaking skills is of utmost importance in the present scenario with an objective to make the job aspirants gainfully employed. Effective speaking skills are incredibly important to the engineering students. It is stated by the CEOs of top companies that the primary things they look for when hiring new employees is how well they are able to communicate. As mentioned earlier, engineering students must possess good speaking skills to face and attend interviews, group discussions, and oral examinations, and make technical presentations etc. They should be able to present themselves effectively in all these activities. Hence, a student of engineering should consciously practice and develop his speaking skills without wasting his precious time any more. 
- Good listening skills: Speaking and Listening are the two sides of a same coin. It is incumbent upon the engineering students to cultivate good listening habits. But listening is often a neglected skill now-a-days. A successful communication process not just comprising of talking but also includes effective listening. One should not forget an important quote that is related to listening - "one cannot become a good communicator unless one is good listener". Many studies have also revealed that business people spend $45 \%$ of their working time for listening. The primary rule that the students remember while listening to someone is to listen deeply without any kind of defensiveness.

- Good writing skills: It is no doubt that good writing is a blessing. Good writing skills are very much essential for effective communication. In this competitive world, the engineering students should know how to write different formal and informal letters, reports, memos and e-mails. In spite of numerous papers written and many presentations made throughout their college career, many of these people will not be able to communicate their engineering skill via written communication. Hence the engineering students of present generation must not ignore these important skills and with continuous practice and hard work they surely augment writing skills.

- Good reading skills: In addition to the above LSW skills reading skills are also most important language skills which are required to the engineering students. Quick, efficient, and imaginative reading techniques are essential in order to achieve academic success. It is said that today's readers are tomorrow's leaders. In view of the need to read vast amounts of materials relating to different fields of knowledge, the engineering students should learn different reading styles such as - skimming, scanning intensive reading and extensive reading and also they must develop a real love for reading which an important segment of Communication skills.

- Body language: Effective communicators are the people who listen to what other people say and continuously give and receive wordless signals. All of our nonverbal behaviors - the gestures we make, the way we sit, how fast or how loud we talk, how close we stand, how much eye contact we make- - send strong messages. This is an essential part of the communication process. Various studies show that the words account for only $7 \%$ of the message you convey. The remaining $93 \%$ is non-verbal. Hence, the engineering students must pay attention to the nonverbal cues and signals they send and receive and with this effort their ability to communicate will improve.

- In addition to the above said skills, engineering students should also develop various important skills such as - team work, leadership skills, critical thinking and problem solving skills etc. With all these necessary skills, an engineering student will undoubtedly become a dynamic professional and technocrat without any doubt.

\section{Some of the most important communicative problems of Engineering Students}

Having been in the teaching field for many years, we have interacted with the hundreds of engineering students in different institutions in Andhra Pradesh state and we came to know various hurdles or problems that are being faced by the student community of engineering and technological institutions. Some of the most important common communicative problems expressed by the students are:

- Lack of confidence: Of late, good communication skills are absolutely vital for everyone for the successful career. Confidence is the key to success. Majority of the engineering students especially Telugu medium and rural area students are found lack of confidence. Interestingly we have come across a few students who are good at English speaking are also unable to speak well by standing before audience due to lack of confidence. It is necessary on the part of engineering students to overcome this hurdle by developing self confidence in themselves.

- The Psychological pressure: We have also heard another common most important communicative problem among the engineering students is the psychological pressure of making mistakes in the presence of their classmates. By having these kinds of psychological feelings, the students are unable to communicate effectively.

- Lack of exposure to English speaking: Since their childhood the students have been speaking in their respective dialects or mother tongue and they do not have proper exposure to speaking in English. 
- Fear and shyness: The surprising note is that most of the engineering students are basically strong in their academic but poor in the segments of communication skills. As a result of this, they do have fear and shyness while communicating with others. Due to these twin hurdles they may remain as ineffective communicators.

- Inadequate practice: This is considered another very important problem among the engineering students. In spite of the fact that they are lagging behind in communication skills, they do not practice more. They are quite aware that they word power is inadequate, poor in sentence construction, poor in listening skills etc. Only a few students who are very serious about their bright future and career will practice well and eventually succeed in their endeavours.

\section{Suggestions to overcome communicative problems of Engineering Students}

Here are the most important suggestions for overcoming the common communicative problems of engineering students:

- Try not being fearful when you are asked to speak in front of the audience.

- Take appropriate steps to enhance your confidence level.

- Try to avail every single opportunity to speak in the public.

- You want to make sure when speaking to someone you are using the right body language, hand gestures, facial expressions, and emotions.

- Practice more to develop all the segments of communication skills with conscious effort.

- Do not bother about errors while communicating with others, instead keep on talking in English.

- Read extensively various news items, articles, magazines, journals etc. in order to boost up your word power and reading skills.

- Carefully observe how proficient speakers of the English language pronounce words and frame their sentences.

- Many online sites offer you the opportunity to voice chat with another user.

- Give your full attention on the person who is speaking.

- Keep writing about something for at least twenty minutes daily. Writing everyday is the key to improving your writing skill.

- Maintain proper eye contact with the person whom you are talking to.

- Make a conscious commitment to strive for better communication skills every day.

- Stop listening to that little negative voice. With a substantial dose of positiveness give a counter-punch on the negative self talk.

\section{Conclusion}

As stated in the introduction, having effective communication skills are indispensable for the successful career of engineering students. Technical skills without communication skills would make a person a knowledge worker but not a manger or leader. This is the harsh reality. A fairly high degree of proficiency in English and excellent communication skills will undoubtedly increase students' employability. Apart from gaining academic knowledge in their core subjects the engineering students have to focus on communications kills so as to become dynamic and efficient communicator which is the very urgent need in the present corporate world.

\section{References}

[1]. Dr. Alex. (2009). Soft skills: Know yourself and know the world. S.Chand \& Co. Publishing House, New Delhi.

[2]. M. Ashraf Rizvi. (2005). Effective Technical Communication. Tata McGraw-Hill Education.

[3]. S. Hariharan, N. Sundrarajan and S.P. Shanmugapriya. (2010). Soft skills. MJP Publishers, Chennai, India.

[4]. http://www.thomasnet.com/journals/career/5-must-have-soft-skills-for-engineers-career-success. 